Izumi, Volume 6, No 2, 2017

e-ISSN: 2502-3535, p-ISSN: 2338-249X

Tersedia online di http://ejournal.undip.ac.id/index.php/izumi

\title{
BAJU BATIK SEBAGAI OMIYAGE : STUDI KASUS PADA MAHASISWA JEPANG YANG PERNAH BELAJAR DI UGM TAHUN 2009-2017
}

\author{
Mery Kharismawati*, Wahyu Handayani.S., \\ Febri Sahrullah. A., Devi Wardhani, $P$ \\ mery.kharismawati@ugm.ac.id
}

Diploma 3 Bahasa Jepang Sekolah Vokasi, Universitas Gadjah Mada

\begin{abstract}
(Title: Batik Clothes As Omiyage: Case Study On Japanese University Students Who Had Studied At UGM In 2009-2017) Batik has long been known as a typical culture of Yogyakarta, and therefore it is most likely chosen by the tourists to take home as souvenir. Until 2017 UGM which is located in Yogyakarta is often visited by students from Japan. As well as studying, they also become tourists who will buy omiyage before returning to Japan. The culture of giving omiyage has existed in Japan since ancient times and until now the term omiyage is still being used for something given to others after traveling. This study aims to determine the relevance of batik clothing as omiyage according to the view of Japanese students who have studied at UGM from 2009-2017. Data were obtained through questionnaire distributed during July 2017 to 60 Japanese students who had studied at UGM. The results of this study indicate that food is still preferred to be omiyage, and batik clothes is not a suitable item to be brought home as omiyage, because of some perceptions about batik clothes as somehing not quite universal to wear in Japan.
\end{abstract}

Keywords: omiyage, batik clothes, Yogyakarta, UGM

\section{PENDAHULUAN}

Batik merupakan salah satu kebudayaan bangsa Indonesia yang telah mendapatkan pengakuan dunia dan telah ditetapkan UNESCO sebagai warisan kemanusiaan untuk budaya nonbendawi pada tanggal 2 Oktober 2009. Saddono et.al (2012) menjelaskan, batik adalah kerajinan yang memiliki nilai seni tinggi dan telah menjadi bagian dari budaya Indonesia sejak zaman dahulu. Menurutnya, Kata "batik" terdiri dari kata amba 'menulis' dan titik 'titik'. Peneliti dari Universitas Indonesia, Dwi Woro Mastuti dalam Senja (2016) lifestyle.kompas.com/read/2016/10/03/1606 00620/cerita.asal-usul.batik.indonesia.

diakses tanggal 6 Oktober 2017, mengatakan bahwa sejak batik resmi menjadi warisan dunia, bermunculanlah kreativitas, dan semua daerah di Indonesia mengadopsi kata 'batik' menjadi salah satu jenis kain.

Di Indonesia, terutama di sentra batik Yogyakarta, baju batik ditawarkan kepada wisatawan sebagai salah satu alternatif oleholeh. Promosi baju batik juga didukung oleh pemerintah Indonesia, yaitu dengan menjadikan tanggal 2 Oktober sebagai "Hari Batik". Pada hari ini, seluruh lapisan masyarakat dianjurkan untuk memakai baju 
batik. Usaha untuk semakin melestarikan batik ini kemudian ditetapkan dalam Keputusan Presiden No. 33 Tahun 2009.

Eksotisme batik membuat batik digemari wisatawan untuk dibawa ke tempat asal mereka sebagai oleh-oleh atau semacam bukti bahwa mereka pernah ke Indonesia, sehingga industri pariwisata tidak dapat dipisahkan dari bisnis oleh-oleh. Dengan demikian, batik merupakan salah satu sektor industri yang penting bagi kota Yogyakarta yang dikenal sebagai kota Batik.

Populernya nama Yogyakarta sebagai kota batik tentu mengundang banyak peneliti untuk mengkajinya. Salah satunya dalam Jurnal Business and Economic Research Macrothink Institute tahun 2015. Hengky, S.H. dalam jurnal tersebut telah mengadakan penelitian berjudul Beneficial Images; Batik Handycraft Tourism in Yogyakarta Indonesia. Tujuan penelitian ini ialah untuk mengetahui performa beneficial image dari batik kerajinan dalam kepariwisataan kota Yogyakarta.

Penelitian berikutnya dari Kundharu Saddhono (2012) dalam International Conferences on Indonesian Studies, ia memaparkan hubungan antara Batik dengan Kimono Jepang. Dalam penelitiannya yang berjudul Batik-Kimono Pengembangan Desain dan Motif dalam Mendukung Industri Kreatif di Indonesia dan Jepang, dikatakan bahwa budaya Jepang dan Indonesia dapat dibandingkan, khususnya dalam bentuk Batik dan Kimono. Pakaian batik sudah semakin dikenal luas di Jepang, dan kebanyakan dikenakan saat acara resmi. Sedangkan kimono, diminati oleh penggemar fashion di Indonesia sebagai suatu model pakaian yang unik. Batik dan Kimono ternyata memiliki motif dan makna filosofis yang saling berhubungan.
Menurut BPS (2012), Yogyakarta masih menjadi destinasi wisata terbaik di Indonesia dengan jumlah wisatawan Jepang yang mencapai 19.074 orang. Jumlah ini cukup tinggi jika dibandingkan dengan destinasi lain di Indonesia. Tidak hanya di bidang pariwisata, kota Yogyakarta yang dikenal sebagai kota pelajar pun menarik perhatian mahasiswa Jepang untuk belajar, khususnya di Universitas Gadjah Mada (UGM). Setiap tahun UGM menerima mahasiswa Jepang yang datang untuk belajar dalam program pertukaran pelajar maupun program lainnya (KUI UGM, 2017). Mahasiswa Jepang ini juga merangkap sebagai wisatawan yang akan turut menjadi konsumen bagi industri pariwisata dan oleh-oleh di Yogyakarta.

Setelah masa studi di UGM berakhir, mahasiswa Jepang akan pulang ke negara asalnya. Saat itulah omiyage, yang dalam bahasa Indonesia berarti 'oleh-oleh' menjadi hal yang terpikirkan sebelum akhirnya mereka berpisah dari kota Yogyakarta.

Berdasarkan latar belakang di atas, penelitian ini bermaksud untuk mencari tahu kesesuaian baju batik sebagai omiyage menurut mahasiswa Jepang yang pernah belajar di UGM dan juga persepsi mereka terhadap baju batik.

\section{METODE PENELITIAN}

Penelitian ini menggunakan metode kuantitatif dan kualitatif dengan instrumen berupa angket yang kemudian dibantu dengan data dari beberapa sumber literatur.

Selama bulan Juli 2017, angket via google angket disebarkan hingga terkumpul 60 responden. Angket yang diberikan memiliki variasi pertanyaan tertutup dan pertanyaan terbuka yang meliputi:

a. Karakteristik responden

b. Pengalaman persinggungan responden dengan batik di Yogyakarta. 
c. Alasan mengenakan batik di Yogyakarta

d. Alasan tidak mengenakan batik di Jepang.

e. Oleh-oleh yang terbayang jika mendengar ada orang yang pulang dari Yogyakarta.

f. Pendapat dan saran responden terhadap baju batik Yogyakarta.

Adapun pembatasan ruang lingkup kajian, yakni lingkup wilayah penelitian (scope spatial), lingkup waktu (scope temporal) dan lingkup materi.

Lingkup wilayah berkaitan dengan tempat yang dijadikan objek penelitian, yaitu Jepang dan Universitas Gadjah Mada di Yogyakarta. Jepang dipilih sebagai lingkup kajian berdasarkan fakta bahwa negara ini memiliki hubungan erat dengan Indonesia bahkan sebelum masa pendudukan Jepang di Indonesia (Wardoyo, 2013). Kerjasama dengan Indonesia meliputi berbagai bidang, mulai dari pariwisata, ekonomi, pendidikan dan bidang lainnya. Lingkup wilayah UGM dipilih sebagai pembatas supaya penelitian terfokus pada mahasiswa Jepang yang pernah belajar di UGM saja. Selain itu UGM sebagai instansi pendidikan juga memiliki peran penting sebagai salah satu sarana untuk memperkenalkan budaya Indonesia pada mahasiswa Jepang yang belajar di sana.

Lingkup waktu dalam penelitian ini ialah dari tahun 2009 hingga 2017. Tahun 2009 merupakan saat diakuinya batik sebagai warisan dunia oleh UNESCO. Hal ini diperkirakan memberikan pengaruh pada pandangan mahasiswa Jepang sewaktu membeli batik sebagai oleh-oleh, maupun menerima batik sebagai oleh-oleh. Sedangkan tahun 2017 menunjukkan tahun ketika mahasiswa Jepang tersebut telah kembali ke negaranya, sehingga dapat dijadikan sebagai responden untuk menjawab angket.
Lingkup materi mencakup baju batik. Pemilihan batasan materi ini didasari oleh semakin berkembangnya industri batik, terutama baju batik yang digadang-gadang pemerintah akan mampu masuk pasar internasional.

Promosi batik berupa "Experience The Wonderful of Indonesia Through Batik Workshop" di ASEAN-Japan Centre yang diselenggarakan oleh kementrian Pariwisata 2015 lalu di Bunka Gakuen University di Tokyo, ternyata menunjukan apresiasi positif dari masyarakat Jepang pada batik, khususnya pakaian (Putri, W.D, (2015). Promosikan Wonderful Indonesia. http://www.republika.co.id/berita/gayahidup/travelling diakses tanggal 2 Maret 2017 ). Baju batik juga muncul dalam Japan Fashion Week tahun 2012 lalu, yang menampilkan peragawati Jepang yang mengenakan baju batik. Dengan acara semacam ini pemerintah berharap dapat meningkatkan animo masyarakat Jepang terhadap baju batik (Fajriana, 2016. Sentuhan Apik batik Dalam Japan Fashion Week 2016. http://lifestyle.liputan6.comread/2349641/se ntuhan-apik-batik-dalam-japan-fashionweek-di-jfw-2016 diakses tanggal 6 Oktober 2017.

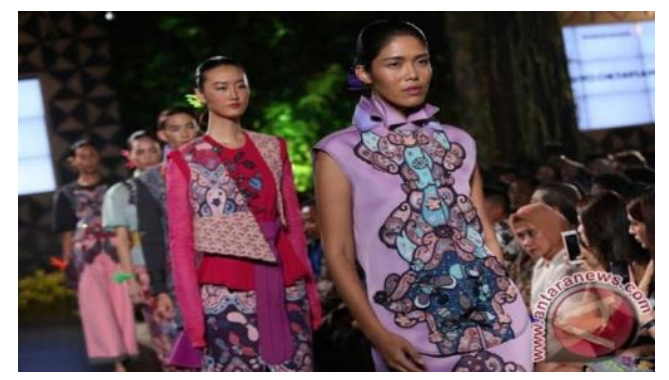

Peragawati Jepang dengan batik Sumber: ANTARA FOTO/ Teresia May www.antaranews.com/berita/532112/jepang-kiansukai-batik-indonesia. Diakses tanggal 2 Oktober 2017 
3. HASIL DAN PEMBAHASAN

\subsection{Asal Mula budaya memberi Omiyage}

Pengertian oleh-oleh dalam bahasa Indonesia ialah sesuatu yang dibawa dari bepergian; buah tangan (KBBI, 2008: 980). Dalam bahasa Jepang, terdapat istilah yang memiliki kemiripan makna dengan kata 'oleh-oleh', yaitu kata omiyage.

Dalam kamus elektronik Kadokawa Ruigo Shin Jiten, omiyage berarti produk setempat, atau produk yang dibawa pulang dari wisata ke luar negeri atau ke daerah lain (Susumu \& Hamanishi, 1987). Sedangkan arti dalam kamus Jepang-Indonesia Kenji Matsuura (1994 : 648), omiyage atau miyage adalah oleh-oleh, buah tangan, suvenir.

Menurut Shimizu (2012) kata miyage ditulis dengan kanji <宮笥〉, yang berarti wadah makanan bagi para dewa. Di akhir ritual keagamaan di Jepang kuno, sesaji berupa bahan makanan mentah, maupun kue-kue di altar akan dinikmati bersama oleh para peziarah. Orang-orang yang makan di acara ini akan membawa pulang sebagian makanan untuk diberikan kepada orang di rumah yang tidak dapat hadir di acara tersebut. Dari sinilah muncul istilah Miyage yang kemudian ditulis dengan kanji <土産> yang berarti produk yang dihasilkan di daerah setempat.

Sesaji saat ritual keagamaan sering berupa makanan khas dari daerah tempat acara tersebut diadakan. Dalam Suzuki (2013) terdapat penjelasan asal mula mengapa asosiasi omiyage sering mengarah pada makanan. Kebiasaan ini berawal dari saat dibukanya jalur Tokaido oleh jawatan kereta api JR di zaman Meiji (1968). Dahulu orang yang berziarah ke kuil menempuh perjalanan jauh dengan berjalan kaki. Karena saat itu belum ada teknologi penyimpanan yang memadai, Omiyage yang dibeli atau diperoleh harus segera dikonsumsi. Keadaan berubah setelah jalur kereta Tokyo-Kobe dibangun. Dengan kecepatan transportasi, Omiyage berupa makanan dapat dibawa pulang dengan segera. Produk makanan kemudian menjadi primadona untuk dijadikan omiyage yang diberikan pada sanak keluarga dan teman-teman.

Omiyage tidak dapat terpisahkan dari kegiatan traveling. Menurut Watkins (2008) banyak catatan perjalanan yang menunjukkan bahwa orang Jepang menyukai kegiatan traveling, misalnya dalam Kiryoka, Manyoshu, Tossa Nikki, dan Kagero Nikki. Ada pula catatan yang ditulis oleh E. Kaempfer seorang dokter Belanda yang tinggal di Nagasaki pada tahun 1691, mengesankan bahwa orang Jepang menyukai kegiatan traveling (Kanzaki, 1997: 100).

Dalam Kanzaki (1997), Watkins (2008), dan Shimamura (2012) dijelaskan bahwa pada awalnya traveling di Jepang ditujukan untuk kegiatan ziarah ke kuil-kuil atau wisata religi. Di zaman Tokugawa (16031868), rakyat jelata dilarang keluar dari daerahnya, kecuali dengan izin khusus, seperti izin untuk memohon jimat ke kuil (ziarah ke kuil). Ada surat khusus yang harus distempel dengan stempel kuil tujuan dan ditunjukkan sebagai bukti bahwa seseorang benar-benar melakukan perjalanan tersebut. Pada perkembangannya, kemudian tidak hanya cap, melainkan produk yang diproduksi di daerah tersebut yang dibawa pulang sebagai bukti. Produk inilah yang kemudian disebut dengan miyage / omiyage (Watkins, 2008).

Aktivitas traveling di Jepang pada zaman feudal membutuhkan kerjasama dari banyak pihak. Mulai dari keluarga hingga pendeta setempat yang turut mendoakan keselamatan si peziarah. Mereka juga mempersiapkan 
Izumi, Volume 6, No 2, 2017

e-ISSN: 2502-3535, p-ISSN: 2338-249X

Tersedia online di http://ejournal.undip.ac.id/index.php/izumi

bekal dan kebutuhan selama perjalanan. Kontribusi masyarakat ini disebut senbetsu. Peziarah kemudian membawakan omiyage sebagai tanda terima kasih kepada mereka yang telah memberikan senbetsu (Watkins, 2008).

Grapburn (1987) dalam Watkins (2008) memaparkan bahwa omiyage harus memenuhi 2 prinsip, yaitu (1) Benda tersebut harus berupa simbol atau barang kenang-kenangan yang berasal dari daerah tujuan (2) Harus seharga senbetsu yang telah diberikan kepada peziarah sebelum keberangkatan.

Budaya saling memberi Omiyage sangat unik. Shimamura et.al (2016) menjelaskan bahwa dalam omiyage tidak terdapat makna kenang-kenangan seperti yang terdapat dalam istilah souvenir dari bahasa Inggris. Bukan pula hadiah yang diberikan pada orang lain yang mengandung nuansa formal karena tujuan tertentu atau penghargaan atas sesuatu. Menurutnya, dalam Omiyage hanya terdapat rasa ingin berbagi kebahagiaan kepada mereka yang tinggal di rumah saja pada saat seseorang bepergian.

\subsection{Hubungan Antara Jepang dengan Batik}

Batik merupakan sebuah proses memunculkan pola pada kain dengan teknik bousen atau menutup sebagian pola dengan lilin (wax-resist) (Tozu, 2016 : 15). Karena keunikan dan kerumitan pembuatan kain batik Indonesia, kemudian batik diakui sebagai salah satu warisan dunia oleh UNESCO pada 2 Oktober 2009. Hal ini didukung dengan pernyataan Koentjoroningrat (1985 dalam Saddhono et.al 2012) menggarisbawahi bahwa kerajinan seni terutama seni Indonesia yaitu tenun, batik, dan tekstil adalah cabang seni yang telah berakar dengan budaya Indonesia selama berabad-abad dengan kualitas tinggi dan mampu menunjukkan karakteristik unik dari Indonesia.

Jepang dan Indonesia telah saling berhubungan bahkan sejak sebelum Jepang menduduki Indonesia di tahun 1942-1945. Sekimoto dalam Yamashita \& Seymour (2002) menjelaskan orang Jepang telah lama mengadakan hubungan dagang dengan pedagang batik dari Jawa, sejak tahun 1920 . Di masa itu terdapat permintaan dari Jepang terhadap produsen batik di Jawa untuk pembuatan obi (sabuk pengikat kimono). Ada pula perusahaan Jepang bernama Fuji Yoko yang mengekspor obi batik tesebut ke Jepang.

Batik dari Jawa disukai masyarakat Jepang di masa pendudukan Jepang. Ini karena terdapat corak bernuansa Jepang pada kainnya. Ayuningtyas (2012) memaparkan bahwa di masa tersebut para pembatik membuat corak-corak seperti Gunung Fuji, Sakura, dan Geisha dalam batik yang dinamakan Jawa Hokokai dan batik Jawa Baru.

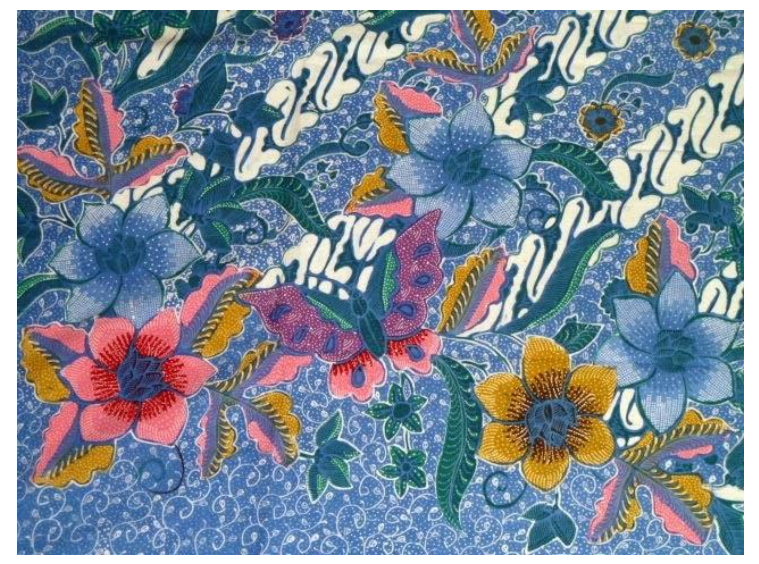

Batik Jawa Hokokai

Sumber:

kancilhouseofbatik.blogspot.co.id/2011/08/batikjawa-hokokai.html

Di Jepang, Batik disebut dengan sarasa. Ito \& Ogasawara (1999) Dalam pengantar bukunya yang mengulas tentang Batik sebagai tradisi yang masih ada hingga sekarang, memaparkan bahwa orang Jepang 
menyukai keunikan pola batik, dan di musim panas dapat dijumpai orang Jepang yang mengenakan batik.

Meskipun banyak orang Jepang yang menyukai batik, ternyata batik dipandang sebagai sebuah objek kultural oleh orang Jepang. Hal ini ditunjukkan dengan artikel tentang batik yang selalu dimuat di pojok budaya di koran-koran Jepang. Di tahun 1991 ketika kaisar Jepang berkunjung ke Indonesia, galeri batik menjadi tujuan yang wajib dikunjungi sebagai perwakilan tradisi budaya Indonesia, bukan sebagai komoditi hasil dari perkembangan industri (Sekimoto dalam Yamashita \& Seymour, 2002).

\subsection{Batik Sebagai Omiyage}

Berdasarkan olah data angket, diperoleh informasi tentang kemungkinan persinggungan mahasiswa Jepang dengan baju batik. Kedatangan mahasiswa Jepang ke Yogyakarta ini ialah untuk belajar di UGM melalui program-program pertukaran pelajar dengan durasi yang beragam. Responden yang menjawab angket adalah sebanyak 60 orang dengan responden lakilaki sebanyak (47\%) dan perempuan sebanyak (53\%). Adapun lama tinggal di Yogyakarta dapat dilihat dari tabel berikut:

Tabel 1 Lama tinggal di Yogyakarta

\begin{tabular}{|c|c|c|c|}
\hline No & Durasi & Jumlah & Prosentase \\
\hline 1 & $<6$ bulan & 13 & $22 \%$ \\
\hline 2 & $\begin{array}{c}<6 \text { bulan-1 } \\
\text { tahun }\end{array}$ & 43 & $72 \%$ \\
\hline 3 & $>1$ tahun & 4 & $6 \%$ \\
\hline & Total & 60 & $100 \%$ \\
\hline
\end{tabular}

Sumber: Data penelitian

Dari angket diperoleh lamanya waktu responden tinggal di Yogkakarta. Sebagian besar responden yang merupakan mahasiswa Jepang ini tinggal selama 6 bulan hingga 1 tahun di UGM (sebanyak 72\%). Kepada responden juga diberikan pertanyaan mengenai apakah responden mengetahui fakta bahwa batik telah menjadi warisan dunia. Dari data penelitian (diagram 1) diperoleh informasi responden yang menjawab 'tahu' sebanyak 48\%, dan sisanya, yaitu sebanyak $52 \%$ tidak mengetahui bahwa batik telah ditetapkan sebagai warisan dunia oleh UNESCO.

Diagram 1. Data Responden Yang Mengetahui Bahwa Batik Telah Ditetapkan Menjadi Warisan Dunia.

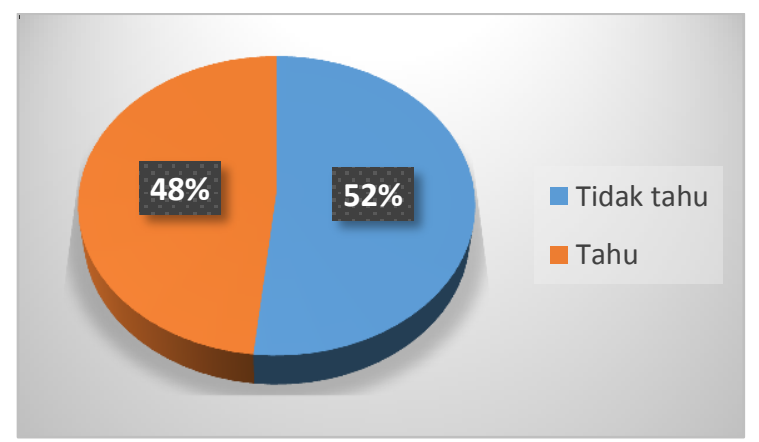

Sumber: Data Penelitian

Prosentase ini tidak terlalu memengaruhi responden untuk bersinggungan dengan baju batik ketika berada di Yogyakarta. Mayoritas responden, baik yang mengetahui maupun yang tidak mengetahui fakta ini tetap mendapatkan pengalaman mengenakan atau membeli batik ketika tinggal di Yogyakarta. Hal ini dapat dibuktikan dengan data berkut:

Tabel 2 Persinggungan dengan baju batik

\begin{tabular}{|l|c|}
\hline Keterangan & Prosentase \\
\hline Pernah membeli baju batik & $93 \%$ \\
\hline $\begin{array}{l}\text { Pernah memakai baju batik di } \\
\text { Yogyakarta }\end{array}$ & $92 \%$ \\
\hline Pernah memakai baju batik di Jepang & $65 \%$ \\
\hline
\end{tabular}

Sumber: Data Penelitian 
Izumi, Volume 6, No 2, 2017

e-ISSN: 2502-3535, p-ISSN: 2338-249X

Tersedia online di http://ejournal.undip.ac.id/index.php/izumi

Dari tabel di atas dapat diketahui bahwa mahasiswa Jepang selama masa belajarnya di UGM menjadi konsumen baju batik. Tingginya prosentase jawaban yang menunjukkan responden membeli batik maupun memakai batik di Yogyakarta (sebanyak 93\% dan 92\%) menunjukkan bahwa batik memang menjadi icon yang wajib dikenal bagi pendatang di kota ini. Adapun alasan mengenakan baju batik menurut mereka dapat dilihat di tabel 3 berikut ini:

Tabel 3. Alasan mengenakan baju batik ketika berada di Yogyakarta

\begin{tabular}{|l|c|}
\hline \multicolumn{1}{|c|}{ Keterangan } & $\%$ \\
\hline Menyukai batik & $68,5 \%$ \\
\hline Ingin mencoba hal yang baru & $27 \%$ \\
\hline Seragam yang wajib dipakai di UGM & $5,6 \%$ \\
\hline $\begin{array}{l}\text { Ingin memakai baju seperti yang } \\
\text { dipakai teman }\end{array}$ & $18,5 \%$ \\
\hline Untuk menghadiri pesta pernikahan & $6,6 \%$ \\
\hline Baju untuk acara formal di Indonesia & $3,3 \%$ \\
\hline Untuk foto kenang-kenangan & $1 \%$ \\
\hline
\end{tabular}

Sumber: Data Penelitian

Sebanyak $68,5 \%$ dari responden mengatakan bahwa mereka menyukai batik, dan dari tabel 2 diketahui sebanyak 93\% responden pernah membeli baju batik ketika berada di Yogyakarta. Meski demikian, hal ini tidak menunjukkan bahwa batik tersebut dijadikan omiyage yang diberikan pada orang lain. Penyebabnya dapat dilihat dari diagram 2 ini:

\section{Diagram 2. Tujuan membeli baju batik}

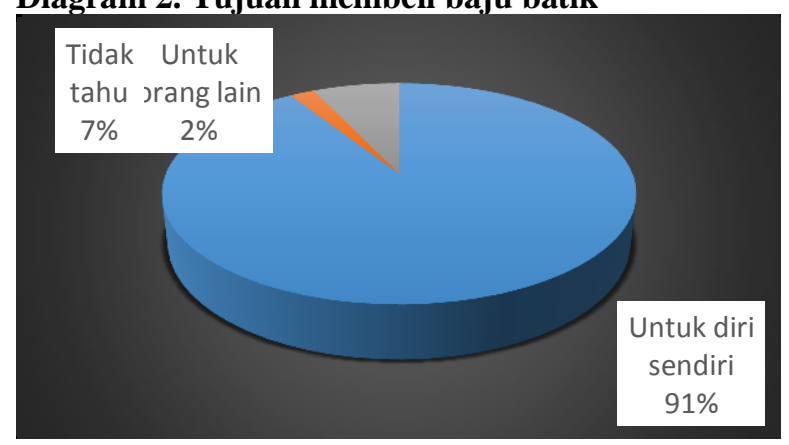

Sumber: Data Penelitian
Diagram 2 di atas memperlihatkan bahwa sebanyak $91 \%$ responden menjawab bahwa tujuan mereka membeli baju batik adalah untuk dipakai sendiri, dan hanya $2 \%$ yang memberikannya untuk orang lain (data penelitian, 2017)

Besarnya prosentase jawaban 'baju batik untuk diri sendiri' menunjukkan bahwa baju batik tidak dibeli sebagai omiyage melainkan karena ada alasan tertentu. Alasan tersebut dapat dilihat di tabel 3, di antaranya karena diwajibkan oleh pihak UGM, untuk menghadiri acara formal, maupun karena ingin mencoba hal yang baru.

Adapun pertanyaan utama yang menjadi sorotan dalam penelitian ini, yakni kesesuaian baju batik sebagai omiyage diwujudkan dengan peberian pilihan produk apa yang terbayang sebagai omiyage dari Yogyakarta. Jawaban yang terangkum menunjukkan data berikut ini:

Tabel 4 Omiyage yang terbayang oleh orang Jepang ketika mendengar ada yang baru pulang dari Yogyakarta

\begin{tabular}{|l|c|c|}
\hline \multicolumn{1}{|c|}{ Keterangan } & Jumlah & $\%$ \\
\hline Makanan khas & 38 & $63 \%$ \\
\hline Aksesori & 24 & $40 \%$ \\
\hline Hiasan interior & 29 & $48 \%$ \\
\hline Baju & 13 & $22 \%$ \\
\hline Kain & 4 & $7 \%$ \\
\hline Kosmetik & 1 & $2 \%$ \\
\hline Kue & 1 & $2 \%$ \\
\hline Sesuatu yang dibeli di Malioboro & 1 & $2 \%$ \\
\hline
\end{tabular}

Sumber : Data penelitian

Pada Tabel 4 diketahui bahwa prosentase tertinggi $(63 \%)$ pada makanan sebagai omiyage yang dibawa pulang dari Yogyakarta. Prosentase tertinggi ke dua merujuk pada aksesori. Kategori ini merujuk pada produk-produk kerajinan yang dijual di sepanjang jalan Malioboro. Sebanyak $48 \%$ responden ternyata menyukai hiasan interior dari Yogyakarta melebihi prosentase responden yang menjawab baju batik untuk 
dijadikan oleh-oleh (sebanyak 22\%). Jawaban ini menunjukkan bahwa mayoritas responden tidak memilih baju batik sebagai omiyage.

\subsection{Persepsi Orang Jepang Terhadap Baju Batik}

Persepsi merupakan hasil kerja otak dalam memahami atau menilai suatu hal yang terjadi di sekitarnya (Waidi, 2006 : 118). Dari penelitian ini dapat terlihat persepsi responden pada baju batik. Persepsi terhadap batik ini merefleksikan alasan responden tidak memilih batik sebagai omiyage. Pada akhir angket yang memuat saran responden mengenai "Batik dari Yogyakarta" dapat terlihat persepsi tersebut. Berikut ini adalah beberapa tulisan responden tentang batik Yogyakarta.

1. Sulit untuk memakai batik di Jepang, karena harus pandai dalam memadukannya dengan baju yang sedang dikenakan, selain harus memperhatikan desain dan warna dari batik itu sendiri.

2. Masih banyak orang yang tidak mengetahui batik, maka sebarkanlah lebih luas lagi mengenai batik.

3. Menurut pendapat saya, kain batik bagus digunakan untuk bahan baju anak-anak jepang.

4. Untuk dikenakan di Jepang, batik mungkin sedikit menyolok, tetapi mungkin batik akan lebih mudah diterima sebagai oleh-oleh apabila digunakan sebagai taplak meja.

5. Ingin diberitahu cara untuk mencegah warna batik menjadi luntur saat dicuci

6. Di Jepang, pola-pola menyolok akan sulit diterima (maka enggan memakai),

7. Saya punya baju batik yang pola batiknya hanya ada di satu bagian (bagian lainnya polos), saya rasa yang seperti ini lebih mudah dikenakan di jepang.

8. Saya rasa terlalu menyolok dan agak memalukan jika dikenakan di luar.

9. Saya ingin orang Jepang memahami bahwa batik itu cocok dipakai di segala suasana baik formal maupun santai.
10. Saya ingin desain pola dan baju batik yang lebih modern. Saya ingin batik lebih dikenal di kancah internasional

\section{Sumber: Data penelitian}

Meski sebelumnya di tabel 3 terdapat $68,5 \%$ responden yang menjawab menyukai batik ketika ditanya alasan memakai baju batik di Yogyakarta, namun di antaranya terdapat responden yang mengatakan bahwa batik terlalu menyolok dan kurang cocok untuk digunakan di Jepang. Hal ini dapat dikaitkan juga dengan persepsi Batik sebagai objek kultural yang telah disebutkan di sub bab 3.2. Sebanyak $65 \%$ responden yang menjawab pernah memakai baju batik di Jepang (tabel 2), menyatakan bahwa mereka memakai baju batik hanya di event yang berkaitan dengan budaya Indonesia (data penelitian, 2017)

Dari tabel 2 diketahui bahwa sebanyak $35 \%$ responden tidak pernah memakai baju batik di Jepang. Adapun alasan mereka adalah sebagai berikut:

Tabel 5. Alasan tidak mengenakan baju batik di Jepang

\begin{tabular}{|l|l|c|}
\hline \multicolumn{1}{|c|}{ Alasan } & Jumlah & $\%$ \\
\hline $\begin{array}{l}\text { Tidak ada kesempatan untuk } \\
\text { memakainya }\end{array}$ & 17 & $48 \%$ \\
\hline Tidak terbiasa & 2 & $12 \%$ \\
\hline Terasa terlalu menyolok & 2 & $12 \%$ \\
\hline $\begin{array}{l}\text { Tidak cocok dipadukan dengan } \\
\text { baju di Jepang }\end{array}$ & 1 & $6 \%$ \\
\hline $\begin{array}{l}\text { Bukan desain yang sesuai untuk } \\
\text { dipakai di Jepang }\end{array}$ & 1 & $6 \%$ \\
\hline Tidak ada & 12 & $34 \%$ \\
\hline
\end{tabular}

Sumber: Data Penelitian

Dari jawaban di atas menunjukkan bahwa batik masih dirasa kurang sesuai untuk dikenakan sehari-hari di Jepang. Jawaban 
responden yang menyatakan memakai baju batik dengan alasan ingin mencoba hal baru (tabel 3), menunjukkan antusiasme mereka terhadap batik hanya terjadi ketika berada di Yogyakarta. Sementara jawaban responden yang memakai baju batik untuk acara formal juga menguatkan asumsi bahwa batik erat dengan budaya Indonesia.

\section{SIMPULAN}

Di Jepang terdapat budaya memberikan omiyage. Berdasarkan sejarahnya, omiyage merupakan produk khas dari daerah yang pernah dikunjungi, yang diberikan kepada orang lain untuk tujuan berbagi pengalaman dan kebahagiaan.

Mahasiswa Jepang di Yogyakarta yang mewakili wisatawan Jepang pada umumnya mengenal batik sebagai komoditi khas dari Yogyakarta dan juga batik sebagai warisan dunia. Meskipun mengetahui bahwa batik merupakan komoditi khas dari Yogyakarta, tetapi hal ini tidak terlalu memengaruhi perilaku konsumen dalam memilih batik untuk dijadikan omiyage. Dari penelitian ini dapat dipahami bahwa makanan masih menjadi pilihan favorit untuk dijadikan omiyage.

Mahasiswa Jepang di Yogyakarta membeli batik untuk digunakan sendiri dan tidak untuk diberikan pada orang lain. Hal ini memiliki kaitan dengan persepsi batik di mata orang Jepang yang erat dengan budaya Indonesia. Erat dengan budaya Indonesia di sini memiiki arti bahwa tidak semua orang dapat mengenakan batik, terutama mereka yang belum pernah ke Indonesia. Maka dari itu, berdasarkan penelitian ini diperoleh fakta bahwa baju batik dirasa kurang universal untuk dapat dikenakan dalam kehidupan sehari-hari di Jepang.

\section{DAFTAR PUSTAKA}

Ayuningtyas, F.E. 2012. Batik as World Intangible Cultural Heritage and Its

Transformation. Association of Pop Culture Studies, A.P.O.C.S ., No.6,

Tokyo, Japan : 2012

http://www.apocs.jp/

Departemen Pendidikan Indonesia. 2008. Kamus Besar Bahasa Indonesia. Jakarta: Balai Pustaka

Ditjen Kementrian Perdagangan Republik Indonesia. 2012. Warta Ekspor; Batik Indonesia, Upaya Mengeksiskan Batik di Kancah Internasional.. Ditjen PEN/MJL/003/1/2012 Edisi Januari

Hengky, S. H. 2015. Beneficial Images: Batik handicraft tourism in Yogyakarta, Indonesia. Journal. Business and Economic Research. Macrothink Institute Vol. 5, No. 1.

Ito, Fusami \& Ogasawara Sae. ( 1999). Jawa Sarasa (Shotor Museum) Ima Ikiru Dentoo. Shogakukan.

Matsuura, Kenji. (1994). Kamus JepangIndonesia. Kyoto Sangyo Univesity: Kyoto Sangyo University Press.

Susumu, Ono \& Hamanishi Masando. 1987. Kadokawa Ruigo Shinjiten. Tokyo: Kadokawa shoten.

Saddhono, Kundharu et.al. 2012. BatikKimono:Pengembangan Desain dan Motif dalam Mendukung Industri Kreatif di Indonesia dan Jepang

Sekimoto, Teruo. Batik As Commodity And Cultural Object. Dalam Yamashita, 
Shinji \& Jeremy, Seymour, E. (editor). 2002. Globalization in Southeast Asia: Local, National, and Transnational Perspectives.

Shimamura, Ayumi, et.al. 2016. Correlational Factors Affecting to Purchase Souvenir Purchase (Omiyage) Among University Students. Hosei Daigaku. Journal for regional policy studies, No: 8, hal. 61-73.

Shimizu, Kiyoko. 2012. Omiyage. Chiiki Kenkyuu Sentaa. Chiiki Bunka Shiriizu 28. Chiiki Mirai Kenkyuu Sentaa. Nikkei Kengeppoo 2012-1.

Suzuki, Yuichiro. 2013. Omiyage to Tetsudo Meibutsu de Kataru Nihon KindaiShi. Kodansha.

Tozu, Masakatsu. 2016. Indonesia Fashion. The World of Ethnic Costumes Bloomed in The Silk Road of the Sea. NHK Service Center.Inc.

Wardoyo, Stedi. 2013. Jawa Dalam Pandangan Imigran Jepang di Hindia Belanda Pada Awal Abad Ke-20. Program Studi Bahasa dan Sastra Jepang Fakultas Ilmu Budaya. EJournal UNDIP. Izumi Jurnal Bahasa, Satra dan Budaya Jepang.

Waidi. 2006. On Becoming A Personal Excellent. Jakarta: PT Elex Media Komputindo.

Watkins, Leah. 2008. Japanese Travel Culture: An Investigation Of The Links Between Early Japanese Pilgrimage And Modern Japanese Travel Behaviour. New Zealand Journal of
Asian Studies. 10, 2 (December 2008): 93-110.

\section{Sumber Internet:}

Aminah. 2015. Kampus Fesyen Ternama Jepang Pelajari Batik,. http://www.republika.co.id/berita/gaya -hidup/trend/15/11/27/nygf9q384kampus-fesyen-ternama-jepangpelajari-batik diakses tanggal 2 Maret 2017

Fajriana, 2016. Sentuhan Apik batik Dalam Japan Fashion Week 2016. http://lifestyle.liputan6.comread/23496 41/sentuhan-apik-batik-dalam-japanfashion-week-di-jfw-2016 diakses tanggal 6 Oktober 2017.

Jakarta.Kompas.com. 2011.Yogyakarta Masih Diminati Turis Jepang. travel.kompas.com/read/2011/04/04/0 9534218/Yogyakarta.Masih.Diminati. Turis.Jepang diakses tanggal 20 September 2017

Mareza, B. 2016. Tradisi memberikan oleholeh . http://student.cnnindonesia.com/inspir asi/20160617141010-322138934/tradisi-oleh-oleh/ diakses tanggal 2 Maret 2017

Putri. W. 2015. Kain Indonesia Dianggap Berikan Inspirasi Tak terhingga. http://www.republika.co.id/berita/gaya -hidup/trend/15/10/03/nvn3rj359-kainindonesia-dianggap-berikan-inspirasitak-terhingga 
Izumi, Volume 6, No 2, 2017

e-ISSN: 2502-3535, p-ISSN: 2338-249X

Tersedia online di http://ejournal.undip.ac.id/index.php/izumi

Putri.W. 2015. Promosikan Wonderful Indonesia.

http://www.republika.co.id/berita/gaya

hidup/travelling/15/11/27/nygogn359-

promosikan-wonderful-indonesia-

kemenpar-gelar-workshop-batik-di-

universitas-jepang

Senja.2016. Cerita Asal-Usul Batik

Indonesia.

http://lifestyle.kompas.com/read/2016/

10/03/160600620/cerita.asal-

usul.batik.indonesia

diakses tanggal 6 Oktober 2017

Supardi. 2015. Jepang Kian Sukai Batik

Indonesia.

http://www.antaranews.com/berita/532

112/jepang-kian-sukai-batik-indonesia

Diakses tanggal 6 Oktober 2017 